\title{
Identification and Characterization of Plant Cell Death-Inducing Secreted Proteins From Ustilaginoidea virens
}

\author{
Anfei Fang, Yanqing Han, Nan Zhang, Min Zhang, Lijuan Liu, Shuai Li, Fen Lu, and Wenxian Sun \\ Department of Plant Pathology; Key Laboratory of Plant Pathology, Ministry of Agriculture, China Agricultural University, Beijing \\ 100193, China
}

Submitted 4 September 2015. Accepted 22 February 2016.

\begin{abstract}
Ustilaginoidea virens (Cooke) Takah (telemorph Villosiclava virens) is an ascomycetous fungus that causes rice false smut, one of the most important rice diseases. Fungal effectors often play essential roles in host-pathogen coevolutionary interactions. However, little is known about the functions of $U$. virens effectors. Here, we performed functional studies on putative effectors in $U$. virens and demonstrated that 13 of 119 putative effectors caused necrosis or necrosis-like phenotypes in Nicotiana benthamiana. Among them, 11 proteins were confirmed to be secreted, using a yeast secretion system, and the corresponding genes are all highly induced during infection, except $U V \_44$ and $U V \_4753$. Eight secreted proteins were proven to trigger cell death or defenses in rice protoplasts and the secretion signal of these proteins is essential for their cell death-inducing activity. The ability of UV_44 and UV_1423 to trigger cell death is dependent on the predicted serine peptidase and ribonuclease catalytic active sites, respectively. We demonstrated that UV_1423 and UV_6205 are $N$-glycosylated proteins, which glycosylation has different impacts on their abilities to induce cell death. Collectively, the study identified multiple secreted proteins in $U$. virens with specific structural motifs that induce cell death or defense machinery in nonhost and host plants.
\end{abstract}

Defense and counter-defense are major themes in host-pathogen coevolutionary interactions (Jones and Dangl 2006). Biotrophic plant pathogens rely on viable host cells and tissues for colonization and multiplication, so these pathogens generally avoid disturbing plant growth and development for their survival. However, pattern recognition receptors in plants can recognize microbe-associated molecular patterns (MAMPs) such as fungal chitin and, thus, initiate pattern-triggered immunity (PTI) (Boller and He 2009; Macho and Zipfel 2014). In order to counteract plant defenses, phytopathogens secrete a great number of effectors into host cells that suppress immune responses by targeting essential components in plant defense signaling (Dou and Zhou 2012; Howden and Huitema 2012). Plants have evolved resistance $(\mathrm{R})$ proteins that specifically recognize certain pathogen effectors, which often induce the hypersensitive response (HR) of host cells, called effector-triggered immunity (ETI)

Corresponding author: W. Sun; Telephone: +86106273 3532; Fax: +86 10 6273 3532; E-mail: wxs@cau.edu.cn

*The $\boldsymbol{e}$-Xtra logo stands for "electronic extra" and indicates that four supplementary figures and seven supplementary tables are published online.

(c) 2016 The American Phytopathological Society
(Chisholm et al. 2006; Jones and Dangl 2006; Stergiopoulos and de Wit 2009).

Unlike bacterial type III effectors, which are all injected into the host cells, the effectors produced by filamentous plant pathogens belong to two major categories, apoplastic and cytoplasmic effectors (Giraldo and Valent 2013). Apoplastic effectors are recognized as avirulence proteins or function as virulence factors in the apoplast of host plants (van Esse et al. 2007), while cytoplasmic effectors have been demonstrated to be delivered into the cytoplasm and act inside the cell (Mentlak et al. 2012). Fungal pathogens are able to secrete a large array of effectors, but only a small subset of effectors has been characterized so far. For example, the apoplastic effector Avr4 in Cladosporium fulvum is required for full virulence and protects the fungus against chitinases when binding to chitin through the chitin-binding domain (van Esse et al. 2007). Another type of chitin-binding effectors, e.g., Slp1 in Magnaporthe oryzae and Ecp6 in C. fulvum, competes with chitin receptors to sequester chitin oligosaccharides through the LysM domains and, thus, perturb chitin-triggered immunity in hosts (de Jonge et al. 2010; Mentlak et al. 2012). The secreted lipase FGL1, which releases free fatty acids to inhibit the activity of callose synthase, is required for virulence of Fusarium graminearum (Blümke et al. 2014; Voigt et al. 2005). Pit2 in Ustilago maydis inhibits the activity of a maize cysteine protease 2 and is essential for full virulence to maize (Mueller et al. 2013). Pep1, a conserved core effector across smut pathogens of dicots and monocots, is required for Ustilago maydis penetration and for inhibition of plant apoplastic peroxidases (Hemetsberger et al. 2012, 2015). In addition, Cmu1 functions as a chorismate mutase, reduces salicylic acid level in maize, and suppresses plant defenses (Djamei et al. 2011). Heterologous expression of $M$. oryzae Avr-Piz-t in rice suppresses oxidative burst and defense-related gene expression induced by MAMPs (Park et al. 2012). Multiple SIX (secreted in xylem) effectors contribute to $F$. oxysporum $\mathrm{f}$. $\mathrm{sp}$. lycopersici virulence and suppress different types of immune responses in tomato (Ma et al. 2010). Barley powdery mildew candidate effectors CSEP0105 and CSEP0162 are required for haustorial formation and contribute to successful infection (Ahmed et al. 2015). Collectively, fungal effectors are among the most important virulence factors and suppress host immunity using various molecular mechanisms (Supplementary Table S1).

Besides functioning as virulence factors to cripple host defenses, fungal effectors are often recognized to trigger host immunity. Four apoplastic effectors Avr2, Avr4, Avr4E, and Avr9 in C. fulvum have been well-characterized to be recognized by receptor-like C. fulvum resistance proteins $\mathrm{Cf}-2, \mathrm{Cf}-4, \mathrm{Cf}-4 \mathrm{E}$, and Cf-9, respectively, in tomato (Luderer et al. 2002; Van der Hoorn 
et al. 2000). Deletion of sixl also disrupted I-3-mediated resistance against $F$. oxysporum $\mathrm{f}$. sp. lycopersici in tomato (Rep et al. 2004). Multiple gene-for-gene interactions have been also revealed in the rice- $M$. oryzae model pathosystem. For example, Avr-Piz-t was shown to be delivered into the infected rice cells and recognized by Piz-t, which induced ETI in rice (Park et al. 2012). Eight other effectors in M. oryzae, PWL1, PWL2, AvrPita, Avr-Pia, Avr-Pii, Avr-Pik/km/kp, Avr1-CO39, and ACE1 are also recognized by the corresponding $\mathrm{R}$ proteins (Chauhan et al. 2002; Kanzaki et al. 2012; Okuyama et al. 2011; Takagi et al. 2013). Multiple effectors in Phytophthora sojae trigger defense responses in Nicotiana benthamiana (Wang et al. 2011). Recently, the apoplastic effector XEG1, a glycoside hydrolase family $12(\mathrm{GH} 12)$ protein in $P$. sojae was identified to act as a MAMP to induce cell death in dicot plants (Ma et al. 2015). During attempted colonization by the nonadapted pathogens, nonhost recognition of effectors is proposed to play an important role in nonhost resistance (Schulze-Lefert and Panstruga 2011; Stam et al. 2014). Four secreted effectors in M. oryzae have been demonstrated to induce nonhost cell death when transiently

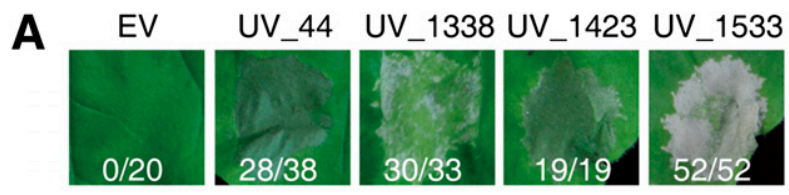

UV_4040 UV_4753 UV_5436 UV_5517 UV_5851
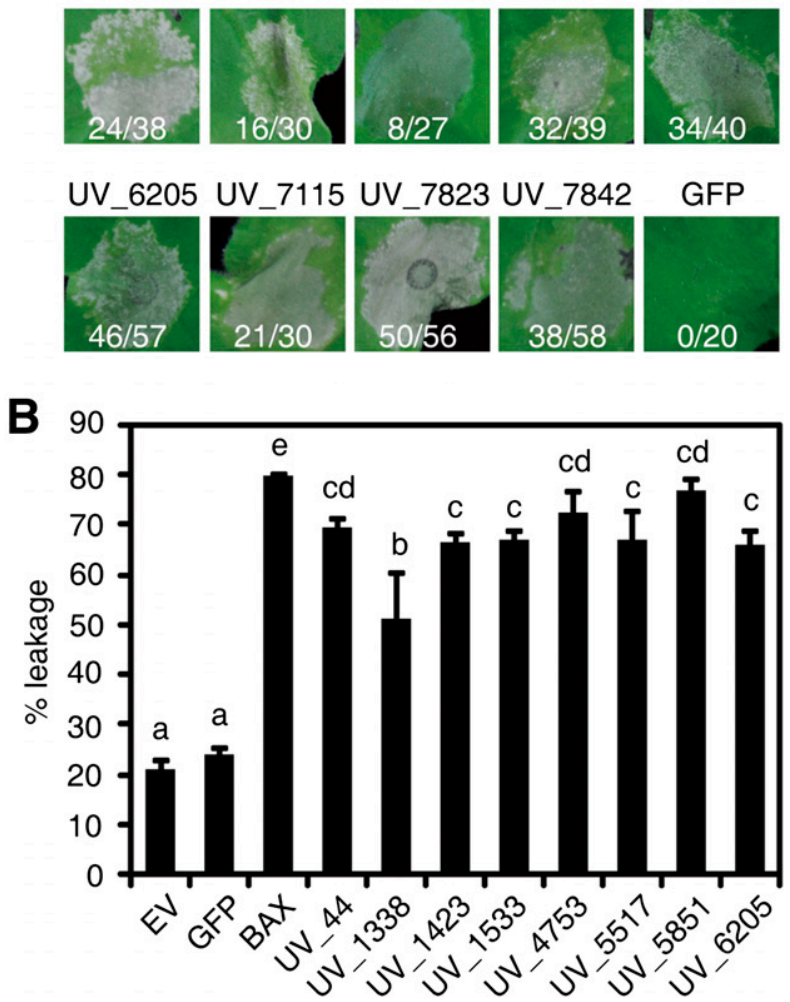

Fig. 1. The putative effectors in Ustilaginoidea virens induce necrotic celldeath phenotypes in Nicotiana benthamiana. A, Transient expression assays of 119 putative $U$. virens effectors revealed that 13 of them caused cell death or mottling symptoms in $N$. benthamiana leaves. Numbers, e.g., $28 / 38$, indicate that 28 of 38 infiltrated leaves exhibited cell death or mottling phenotypes. EV = empty vector; GFP = green fluorescent protein. Representative photos were taken at 5 days after infiltration. B, Quantification of cell death in the infiltrated $N$. benthamiana leaves by measuring ion leakage. Ion leakage from the leaf discs infiltrated with different gene constructs was measured at 4 days after infiltration. The EV, GFP, and $B A X$ constructs were infiltrated as negative controls and a positive control, respectively. Data are means \pm standard error (SE) from three independent experiments. expressed in N. benthamiana (Chen et al. 2013). Therefore, fungal effectors are often recognized to initiate resistance or defense signaling pathways in plants.

Ustilaginoidea virens is the causal agent of rice false smut (RFS), which has recently expanded rapidly and become one of the most important rice diseases worldwide (Rush et al. 2000; Singh and Pophaly 2010; Tanaka et al. 2008; Tang et al. 2013). As a flowerinfecting fungus, $U$. virens initially colonizes on rice florets during the booting stage and, consequently, chlamydospore-covered sporeballs are formed on the infected spikelets (Hu et al. 2014; Tang et al. 2013). The ovaries of infected spikelets remain alive at the late stage of infection. Therefore, $U$. virens is considered to be a biotrophic pathogen (Tang et al. 2013; Zhang et al. 2014). Different types of mycotoxins, including ustiloxins and ustilaginoidins, are produced in the sporeballs and are toxic to human and animals by inhibiting cell division (Shan et al. 2012). RFS not only causes significant yield loss in the staple food crop but, also, brings severe threat to food safety.

Based on genome sequence, $U$. virens encodes at least 193 small secreted cysteine-rich proteins, which are considered as effector candidates (Zhang et al. 2014). Transcriptome analyses during infection and HR inhibitory assays in $N$. benthamiana suggest that a subset of putative effectors is an essential component for successful infection of $U$. virens (Zhang et al. 2014). However, it is still a mystery whether the effectors in $U$. virens can be recognized and, thus, trigger cell death or defense responses in the host and nonhost plants. In this study, we investigated the cell deathinducing ability of 119 putative effectors in $U$. virens through transient expression assays. Eleven and eight putative effectors were found to induce cell death in $N$. benthamiana and rice protoplasts, respectively. The predicted active sites of a secreted serine peptidase and a putative ribonuclease-like effector were shown to be required for their cell death-inducing activity. Our results also indicate that $\mathrm{N}$-glycosylation is a typical modification for these fungal cell death-inducing factors, which glycosylation might have important roles in their functions and stability.

\section{RESULTS}

A subset of putative effectors

in $U$. virens induce cell death in $N$. benthamiana.

To experimentally identify potential $U$. virens effectors that induce cell death in plants, 119 predicted effector genes were amplified and were subcloned into the glucocorticoid-inducible pTA7001 binary vector (Aoyama and Chua 1997). The ability of these putative effectors to induce nonhost cell death was investigated through Agrobacterium-mediated transient expression in $N$. benthamiana. Among the 119 gene constructs, 13 were demonstrated to trigger cell death or mottling in N. benthamiana leaves, but infiltration of the empty vector or green fluorescent protein $(G F P)$ construct did not induce necrosis (Fig. 1). Necrosis severity in the infiltrated leaf areas caused by these effector candidates varied. UV_1423 and UV_1533 induced severe cell death rapidly at 36 to $48 \mathrm{~h}$ after dexamethasone (DEX) spraying, which induces expression of the infiltrated gene constructs. Necrosis phenotypes induced by UV_1338, UV_4040, UV_4753, UV_5436, UV_5517, UV_5851, UV_6205, UV_7115, UV_7823, and UV_7842 appeared slightly later, at 3 days after DEX treatment. In addition, UV_44 induced a delayed but severe cell death at 5 to 6 days after agroinfiltration. Since ion leakage is positively correlated with cell death (Mittler et al. 1999), the molecular feature was quantified to further confirm cell death triggered by these putative effectors. The results showed that ion leakage from $N$. benthamiana leaves transiently expressing eight individual effector candidates was all significantly elevated compared with GFP-expressing or empty vector-infiltrated leaves (Fig. 1B). As a positive control, 
BAX-expressing leaves exhibited the highest ion leakage (Fig. 1B). Together, the results suggest that the 13 putative effectors are recognized by the defense machinery of $N$. benthamiana or that they function as toxins to induce necrosis.

\section{Functional validation}

of predicted signal peptides (SPs) of putative effectors.

An elegant yeast secretion system has been developed to track the secretion of proteins (Jacobs et al. 1997; Oh et al. 2009; Tian et al. 2011). Here, the system was exploited to experimentally corroborate SP prediction for the 13 nonhost cell death-inducing factors in $U$. virens. The predicted SP nucleotide sequence of each gene was fused in frame with the truncated SUC2 gene that encodes invertase lacking its own SP. The fusion constructs were transformed into the invertase secretion-deficient yeast strain YTK12. In the assay, the invertase with bona fide SP, which guides the enzyme to secrete into the medium, can degrade raffinose into simple sugars so that YTK12 can grow on the medium with raffinose as sole carbon source. As a positive control, the secretion signal of $P$. sojae Avr1b led the secretion of invertase and, therefore, YTK12 grew on the raffinose-containing YPRAA (1\% yeast extract, $2 \%$ peptone, $2 \%$ raffinose, and $2 \mu \mathrm{g}$ of antimycin A per liter) medium (Fig. 2). Likewise, the predicted signal peptides of 11 putative effectors restored the ability of invertasedeficient yeast to grow on YPRAA medium. By contrast, the yeast strains transformed with the SP sequences of $U V_{-} 4040$ and $U V_{-} 7823$ as well as a negative control, the N-terminus of Mg87 in M. oryzae (Gu et al. 2011), did not grow on YPRAA plates, suggesting that the N-terminal peptides of the two proteins are not able to guide secretion of the truncated invertase (Fig. 2). These results indicate that the predicted SPs of the 11 putative $U$. virens effectors are functional to direct these proteins to the secretory pathway and that these proteins are bona fide secreted proteins.
Expression analysis of 11 putative effector genes during $U$. virens infection of young panicles.

The effector genes in filamentous plant pathogens are often transcriptionally induced during infection (Stergiopoulos and de Wit 2009). In order to reveal regulation of effector gene expression during $U$. virens infection, the highly virulent isolate P1 was artificially inoculated into young panicles of the rice cultivar IR28, which shows high field resistance to P1, and the cultivar LYP9, which is highly susceptible to P1 (Han et al. 2015). The expression of the 11 secreted protein-encoding genes at $0,24,48$, and $96 \mathrm{~h}$ postinoculation (hpi) was detected by quantitative real time reverse transcription-polymerase chain reaction (RT-PCR) (Fig. 3). These genes are generally categorized into three groups based on their expression profiles during infection. The first group includes $U V \_44$ and $U V \_4753$, in which expression was suppressed during infection (Fig. 3). The other two groups have nine genes, of which expression was all up-regulated to different levels from approximately twofold to approsimately 18-fold. The second group of effector genes, i.e., $U V \_1533, U V \_5436, U V \_5517$, and $U V \_7842$, were transcriptionally up-regulated and gradually increased during infection, while gene expression of the third group, i.e., $U V_{-} 1338$ and $U V \_5851$, was initially induced at the early infection stage and decreased at 96 hpi. The results demonstrated that all 11 secreted protein-encoding genes were differentially regulated during $U$. virens infection, indicating that these secreted proteins are likely effectors and might play important roles in the interaction of rice and the fungal pathogen.

\section{Cell death in rice protoplasts}

induced by the 11 secreted proteins.

To determine whether the 11 secreted proteins trigger host cell death, transient expression in rice protoplasts was performed via a polyethylene glycol (PEG)-mediated transformation system (Chen et al. 2013). In this assay, the constructed plasmids
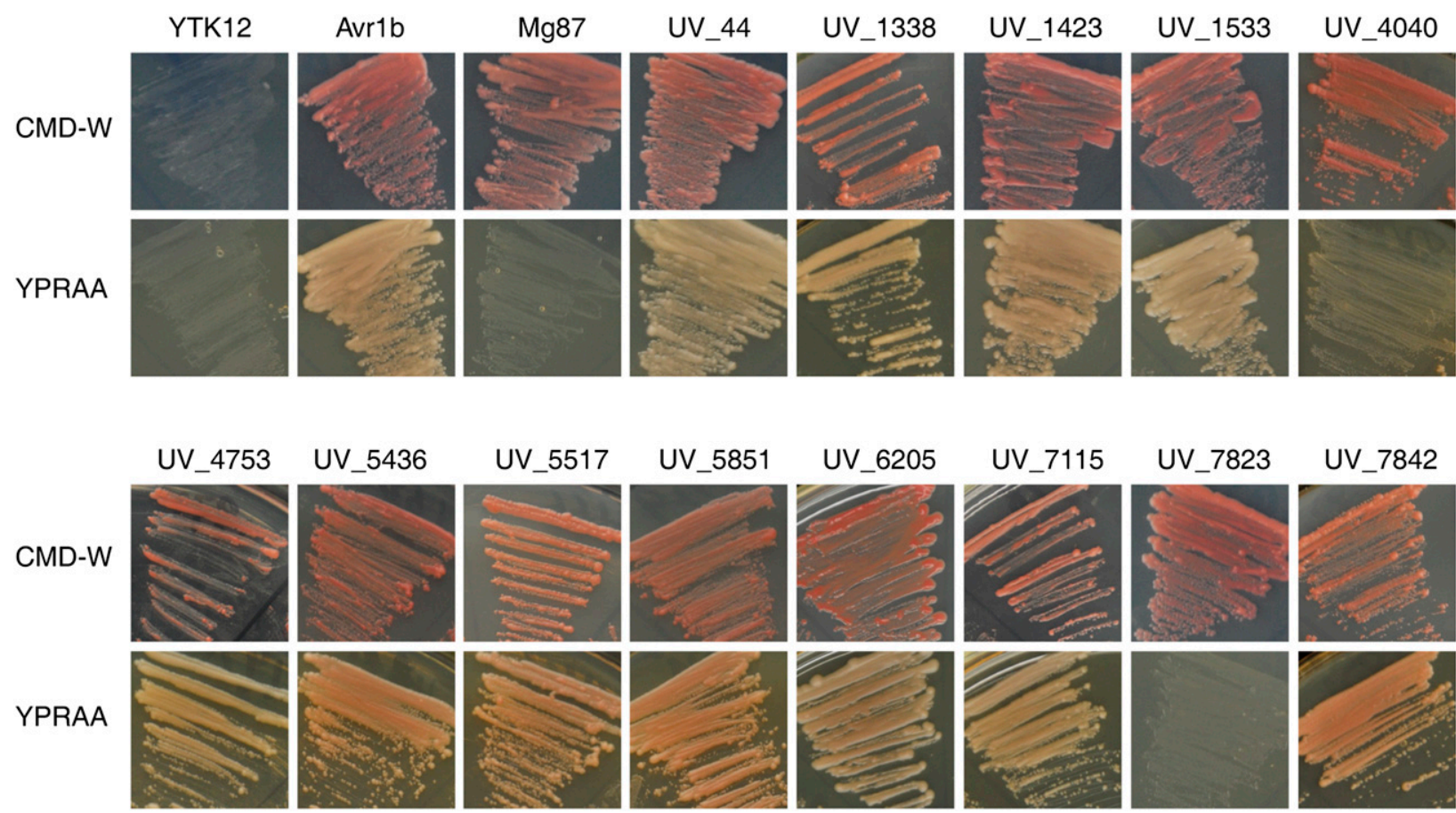

YPRAA

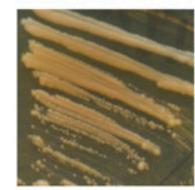

Fig. 2. Functional validation of signal peptides of putative Ustilaginoidea virens effectors using a yeast invertase secretion assay. The predicted SPs of 11 of 13 $U$. virens putative effectors, excepting UV_4040 and UV_7823, can guide the secretion of the truncated invertase lacking signal sequence, and therefore, these transformed yeast YTK12 strains were able to grow on YPRAA media with raffinose as sole carbon source (1\% yeast extract, $2 \%$ peptone, $2 \%$ raffinose, and $2 \mu \mathrm{g}$ of antimycin A per liter). The N-terminal sequences of Phytophthora sojae Avr1b and Magnaporthe oryzae Mg87 were used as positive and negative controls, respectively. The untransformed YTK12 did not grow on either CMD-W (0.67\% yeast N base without amino acids, $0.075 \%$ tryptophan dropout supplement, $2 \%$ sucrose, $0.1 \%$ glucose, and $2 \%$ agar) or YPRAA media. Yeast growth on CMD-W media showed an equal viability of the transformed strains. 
carrying the complete coding sequence of individual secreted protein-encoding genes were cotransformed into rice protoplasts with pJD301-35S-LUC, by which luciferase (LUC) is expressed under the control of the $35 \mathrm{~S}$ promoter (Luehrsen et al. 1992). Induced cell death in rice protoplasts was evaluated by measurement of LUC activity in the protoplasts isolated from rice cv. Nipponbare (Okuyama et al. 2011; Yoshida et al. 2009). As compared with the luminescence intensity detected in the protoplasts cotransformed with the GFP construct, LUC activity in rice protoplasts was significantly reduced when eight individual secreted protein-encoding genes were coexpressed with LUC, respectively. In particular, transient expression of UV_1423 and UV_6205 caused cotransfected protoplasts to completely lose LUC activity (Fig. 4A). By contrast, expression of UV_5436, UV_7115, and UV_7842 in rice protoplasts did not have any inhibitory effect on LUC activity. Transient expression of these secreted proteins, except UV_5517, in rice protoplasts was clearly detected via immunoblotting (Fig. 4B). To confirm that
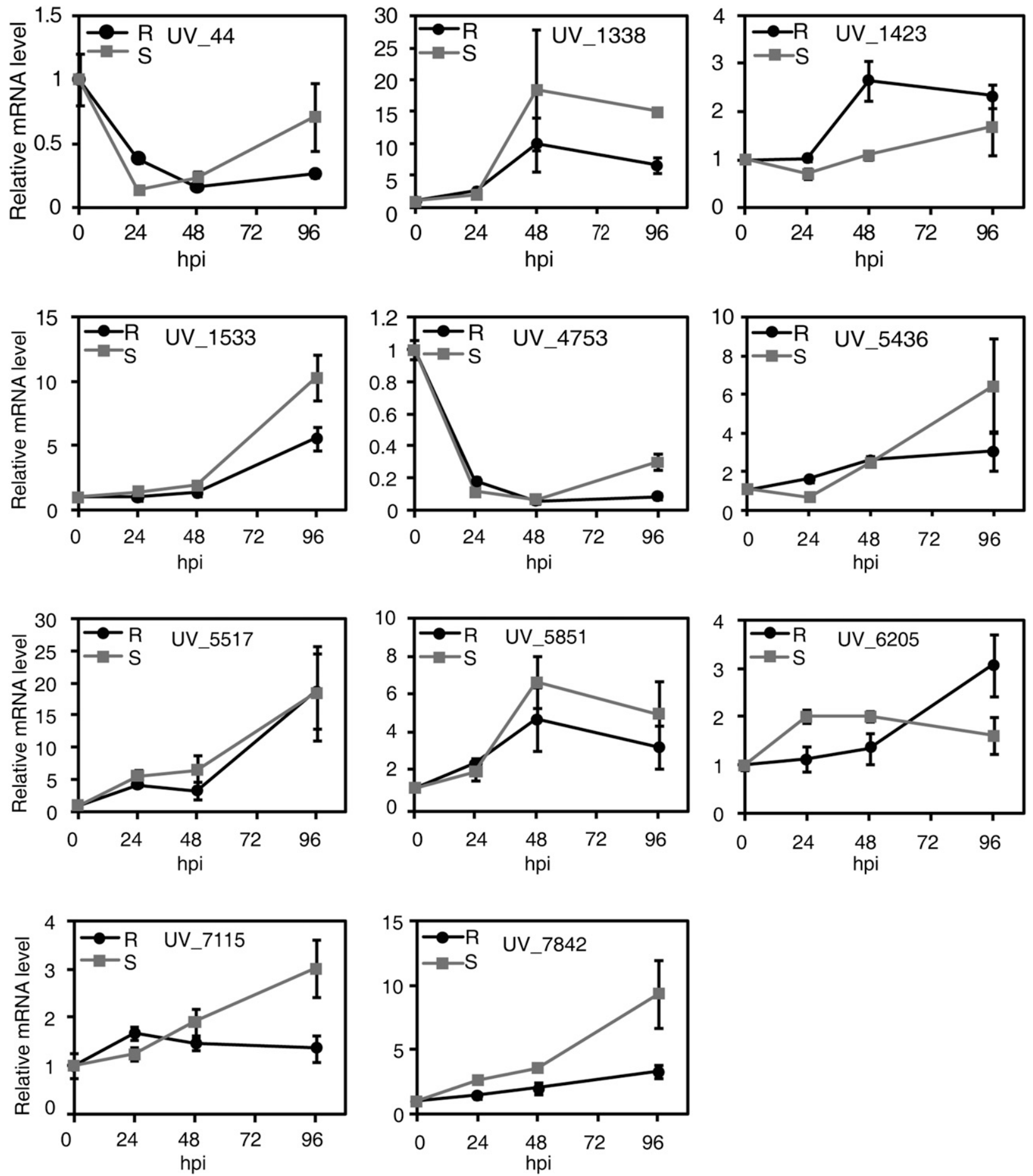

Fig. 3. Expression profiles of 11 putative effector genes during Ustilaginoidea virens infection of the false smut-resistant and -susceptible rice cultivars. The U. virens-inoculated panicles of the false smut-resistant cultivar IR28 (R) and susceptible cultivar LYP9 (S) were collected at 0 , 24, 48, and 96 h postinoculation (hpi) for gene expression analyses using quantitative real time reverse transcription-polymerase chain reaction assay. Data are means \pm standard error. Gene expression patterns shown are representatives from three independent repeats with similar results. 
the reduced LUC activity was associated with cell death, the viability of $U V \_6205$-transfected protoplasts was determined after fluorescein diacetate (FDA) staining. The result showed that $U V \_6205$-transfected protoplasts have a significantly lower surviving rate compared with $G F P$-transfected protoplasts (Fig. 4C). Furthermore, we investigated if the eight secreted proteins are able to induce cell death in the highly susceptible cultivar LYP9 (Han et al. 2015). Transient expression in rice protoplasts showed that these putative effectors, except UV_1338, inhibited LUC activity, which was similar to the result from Nipponbare (Supplementary Fig. S1). All these experimental data suggest that certain putative $U$. virens effectors are able to trigger cell death in rice.

\section{SPs of putative $U$. virens effectors are required} for their ability to trigger plant cell death.

The SP of multiple $M$. oryzae effectors has been demonstrated to be required for their ability to induce cell death in plants (Chen et al. 2013). Here, we determined whether these $U$. virens cell death-inducing factors without SPs remain to have the cell death-inducing ability. Transient expression assays in $N$. benthamiana leaves were first performed to determine the cell death-inducing ability of these putative $U$. virens effectors with or without SPs. The tested secreted proteins with SPs repeatably induced cell death, but all of the truncated proteins lacking SPs no longer caused any cell-death phenotypes (Fig. 5A). Protein gel blots showed that, in most cases, both full-length and truncated proteins were expressed in the infiltrated leaves (Fig. 5A). The requirement of SP for putative $U$. virens effectors to cause cell death was also evaluated in rice protoplasts. As compared with the full-length proteins, SP truncation of all tested putative effectors caused the proteins to completely or partially lose the ability to reduce the LUC activity in cotransfected protoplasts (Fig. 5B). The truncated proteins were all well-expressed in rice protoplasts, although some of them had a lower molecular weight than full-length proteins (Supplementary Fig. S2). In addition, FDA vital staining showed that viable cells in $G F P$ - and $U V \_6205 N S P$-transfected protoplasts were much more than $U V \_6205$-transfected protoplasts (Fig. 4C). Taken together, the results indicate that SPs of the tested secreted proteins in $U$. virens are all required for their ability to trigger cell death in $N$. benthamiana and in rice.

\section{The predicted catalytic triad of serine protease in $U V_{-} 44$ is essential for its ability to induce cell death.}

UV_44 was predicted to be a modular protein that contains a SP, an N-terminal inhibitor_I9 domain, and a conserved peptidase_S8 domain, through Pfam search. The protein belongs to a family of subtilisin-like serine proteases, which appear to have convergently evolved an Asp/His/Ser catalytic triad (Ekici et al. 2008). To analyze the importance of the predicted protease activity of UV_44 in inducing cell death, the residues Asp143, His175, and Ser330, which form the catalytic triad of UV_44, were replaced with alanine (Fig. 6A). The cell death-inducing ability of UV_44 and the mutant proteins $\mathrm{UV} \_44^{\mathrm{D} 143 \mathrm{~A}}$, UV_44 ${ }^{\mathrm{H} 175 \mathrm{~A}}$, and UV_44 ${ }^{\mathrm{S} 330 \mathrm{~A}}$ was first evaluated in $N$. benthamiana. While UV_44 expression caused an evident cell death, the mutant proteins UV_44 ${ }^{\mathrm{D} 143 \mathrm{~A}}, \mathrm{UV}_{-} 44^{\mathrm{H} 175 \mathrm{~A}}$, and UV_44 ${ }^{\mathrm{S} 330 \mathrm{~A}}$ did not induce necrosis symptoms in the infiltrated areas (Fig. 6B). The wild type and three variants of $U V \_44$ have similar mRNA and protein expression levels detected by RTPCR and Western blotting (Fig. 6C and D). Consistently, UV_44 but not the mutant proteins caused a significant reduction in LUC activity when coexpressing with LUC in rice protoplasts, suggesting that the mutant UV_44 proteins lose the ability to induce cell death in rice (Fig. 6E; Supplementary Fig. S3A). These results indicate that the predicted catalytic triad of serine protease is required for the ability of UV_44 to induce cell death in nonhost and host plants.

\section{The predicted RNase active site} of UV_1423 is essential for its cell death-inducing ability.

UV_1423 was predicted to contain a conserved fungus-specific RNase domain and a C-terminal transmembrane domain. To investigate whether the potential RNase activity of UV_1423 is required for its ability to induce cell death, point mutations were introduced into the predicted active site of the conserved RNase domain. The key residues His60, Glu79, or His113 of UV_1423 necessary for RNase activity were replaced with alanine (Fig. 7A).
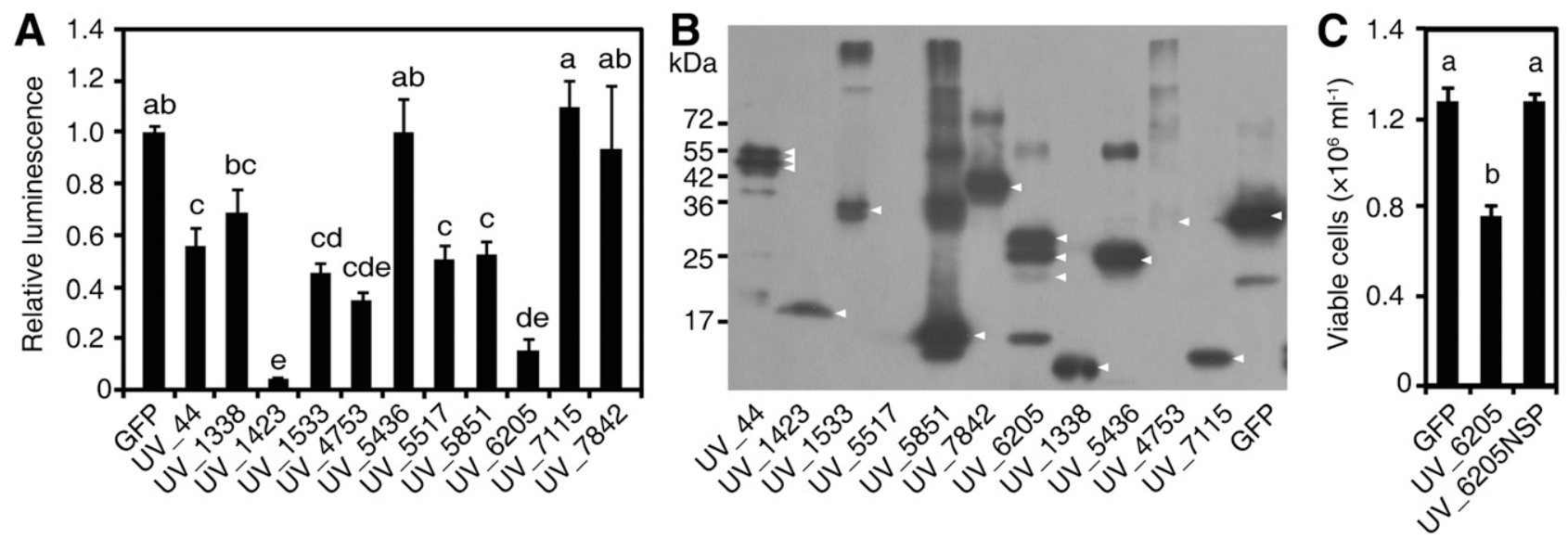

Fig. 4. Transient expression of the putative Ustilaginoidea virens effector genes induces cell death in the protoplasts of rice cv. Nipponbare. A, The activity of luciferase that was transiently expressed in rice protoplasts was significantly inhibited by coexpression of eight individual putative effector genes. Three secreted proteins, including UV_5436, UV_7115, and UV_7842, that induced cell death in Nicotiana benthamiana did not affect the luciferase activity when coexpressed in rice protoplasts. Data are means \pm standard error (SE). Different letters (a through e) indicate significant difference in the luciferase activity at $P<0.05$, according to Duncan's multiple-range test. B, Transient expression of different secreted proteins in rice protoplasts detected by immunoblotting with an anti-FLAG antibody. The correct bands for expressed proteins are indicated by white triangles. GFP = green fluorescent protein. C, Viability of rice protoplasts transfected with GFP, UV_6205, and $U V \_6205 N S P$ gene constructs revealed by fluorescein diacetate (FDA) staining. The protoplasts that can be stained with FDA were counted as viable cells. The GFP-transfected protoplasts were stained as a control. NSP $=$ truncated proteins lacking SPs. Data are means \pm SE. Different letters (a or b) indicate significant difference in the number of viable cells at $P<0.05$, according to Duncan's multiple-range test. 
Cell-death symptoms were observed after different $U V \_1423$ variant constructs were infiltrated into $N$. benthamiana leaves. Consistently, the full-length UV_1423 caused rapid cell death in $N$. benthamiana. However, expression of UV_1423 ${ }^{\mathrm{H60A}}$ and UV_1423 ${ }^{\mathrm{H} 113 \mathrm{~A}}$ in $N$. benthamiana did not induce cell death, while UV_1423 ${ }^{\mathrm{E} 79 \mathrm{~A}}$ caused a less severe necrosis phenotype than the wild-type protein (Fig. 7B). Although mRNA expression of $U V_{-} 1423$ and its variants was at the similar level, Western blot analysis demonstrated that accumulation of UV_1423 and UV_1423 ${ }^{\mathrm{E} 79 \mathrm{~A}}$ was surprisingly low in $N$. benthamiana leaves. By contrast, UV_1423 ${ }^{\mathrm{H} 60 \mathrm{~A}}$ and $\mathrm{UV} \_1423^{\mathrm{H} 113 \mathrm{~A}}$ were more abundant in the infiltrated leaves (Fig. $\overline{7} \mathrm{C}$ and D). Furthermore, detection of LUC activity in cotransfected rice protoplasts showed that the three mutant proteins completely or partially lost the ability to induce cell death in rice (Fig. 7E). These results indicate that the putative RNase active site of UV_1423 is essential for its ability to induce plant cell death.

\section{$N$-linked glycosylation \\ of putative effector proteins in $U$. virens.}

Many effector proteins in filamentous fungal pathogens are predicted to be $\mathrm{N}$-glycosylated. $\mathrm{N}$-glycosylation of the $M$. oryzae effector Slp1 has been recently demonstrated to be required for the rice blast fungus to evade host innate immunity (Chen et al. 2014). To initially investigate the effect of $\mathrm{N}$-glycosylation on the function of putative effector proteins, the online NetNGlyc 1.0 Server was used to predict $N$-linked glycosylation for the identified cell death-inducing factors in $U$. virens. The $N$-glycosylation sites were predicted in six secreted proteins including UV_44, UV_1423, UV_1533,
A<smiles>[As]</smiles>

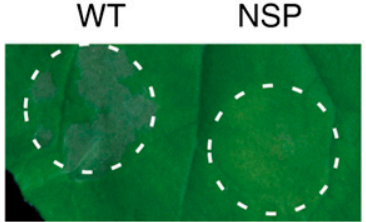

UV_1338

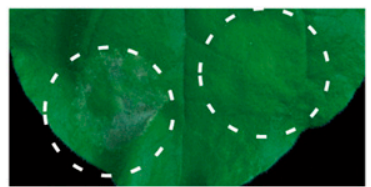

UV_1423

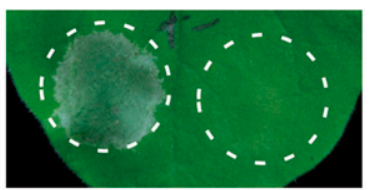

UV

_1533

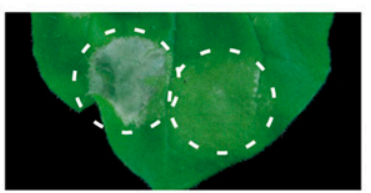

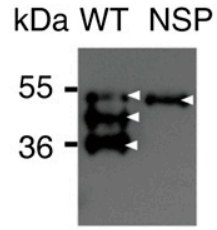
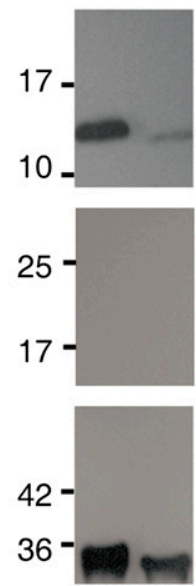

UV 4753
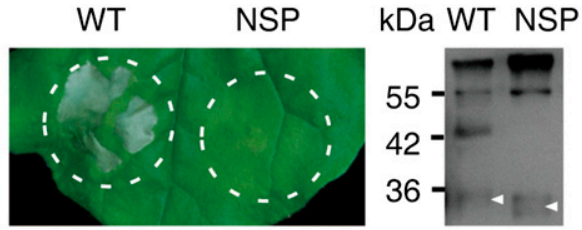

UV_5517


UV_5851
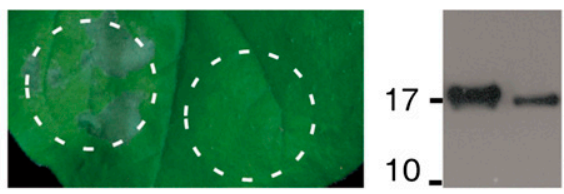

UV_6205
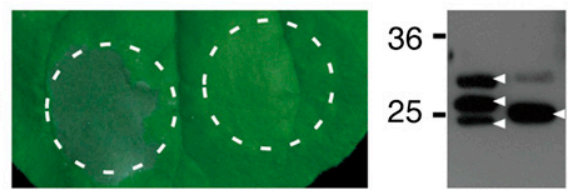

B

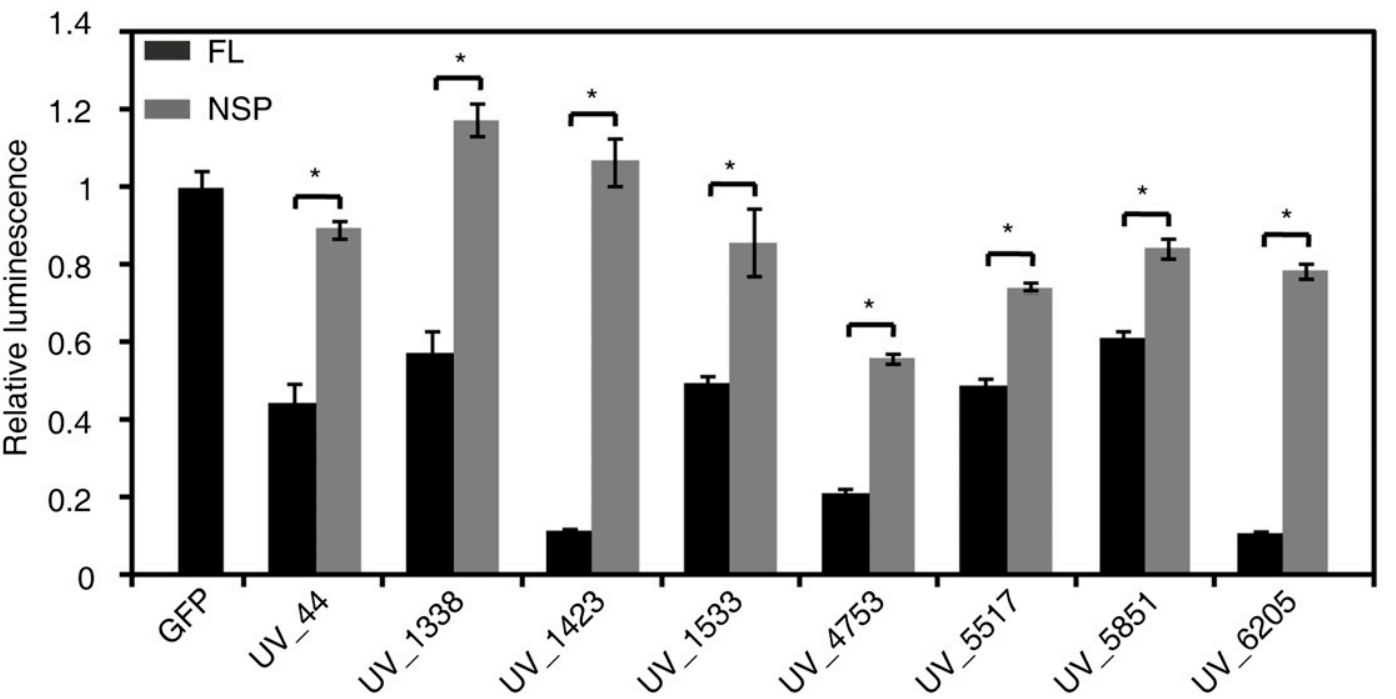

Fig. 5. The truncated Ustilaginoidea virens secreted proteins lacking signal peptides (SPs) are not able to induce plant cell death. A, The truncated $U$. virens secreted proteins without SPs did not cause cell death in Nicotiana benthamiana leaves. Left panels, cell-death symptoms caused by transient expression of full-length and truncated secreted proteins. Right panels, expression level of full-length and truncated proteins in N. benthamiana detected by Western blotting. The correct bands for expressed proteins were indicated by white triangles. B, The truncated $U$. virens secreted proteins without SPs completely or partially lost the inhibitory effect on the luciferase activity in rice protoplasts. Data are means \pm standard error. Asterisks (*) indicate significant difference in the luciferase activity of full-length and truncated effector gene-transfected protoplasts $(P<0.05$, Duncan's multiple-range test $)$. WT $=$ wild-type; NSP $=$ truncated effectors lacking SPs; FL = full-length proteins. 
UV_4753, UV_5436, and UV_6205. UV_1423 and UV_6205 were chosen to be studied further. To verify $N$-glycosylation of the two putative effectors, transiently expressed proteins in $N$. benthamiana were subject to immunoblotting after treatment with Endoglycosidase $\mathrm{H}$ (Endo $\mathrm{H}$ ), which cleaves between the $\mathrm{N}$-acetylglucosamine residues of the chitobiose core of high mannose and some hybrid structures from $\mathrm{N}$-linked glycoproteins. The results showed that UV_1423 ${ }^{\mathrm{H} 60 \mathrm{~A}}$ and UV_6205 became smaller after the treatment with Endo $\mathrm{H}$, indicating that both proteins are glycosylated (Supplementary Fig. S4). It is notable that UV_1423 ${ }^{\mathrm{H} 60 \mathrm{~A}}$ was used for deglycosylation experiments, because the expression of wild-type UV_1423 was barely detectable in $N$. benthamiana (Fig. 5). To further characterize the $N$ glycosylation sites of UV_1423 and UV_6205, mutant proteins with point mutations in their predicted $\mathrm{N}$-glycosylation sites were transiently expressed in rice protoplasts. The apparent molecular weight of UV_6205 ${ }^{\mathrm{N} 39 \mathrm{G}}, \mathrm{UV} \_6205^{\mathrm{N} 53 \mathrm{G}}$, and UV_6205 ${ }^{\mathrm{N} 39 \mathrm{G} / \mathrm{N} 53 \mathrm{G}}$ was clearly lower than UV_6205, suggesting that both Asn39 and Asn53 are linked with $\mathrm{N}$-glycans (Fig. 8A). Likewise, UV_1423 ${ }^{\mathrm{H} 60 \mathrm{~A}}$ expressed in rice protoplasts was cleaved by Endo $\mathrm{H}$, while UV_1423 ${ }^{\mathrm{H} 60 \mathrm{~A} / \mathrm{N} 49 \mathrm{G}}$ cannot be cleaved further. The molecular weight of $\mathrm{UV}_{-} 1423^{\mathrm{H} 60 \mathrm{~A} / \mathrm{N} 49 \mathrm{G}}$ is evidently smaller than UV_1423 ${ }^{\mathrm{H} 60 \mathrm{~A}}$ (Fig. 8B). The results suggest that Asn49 is the
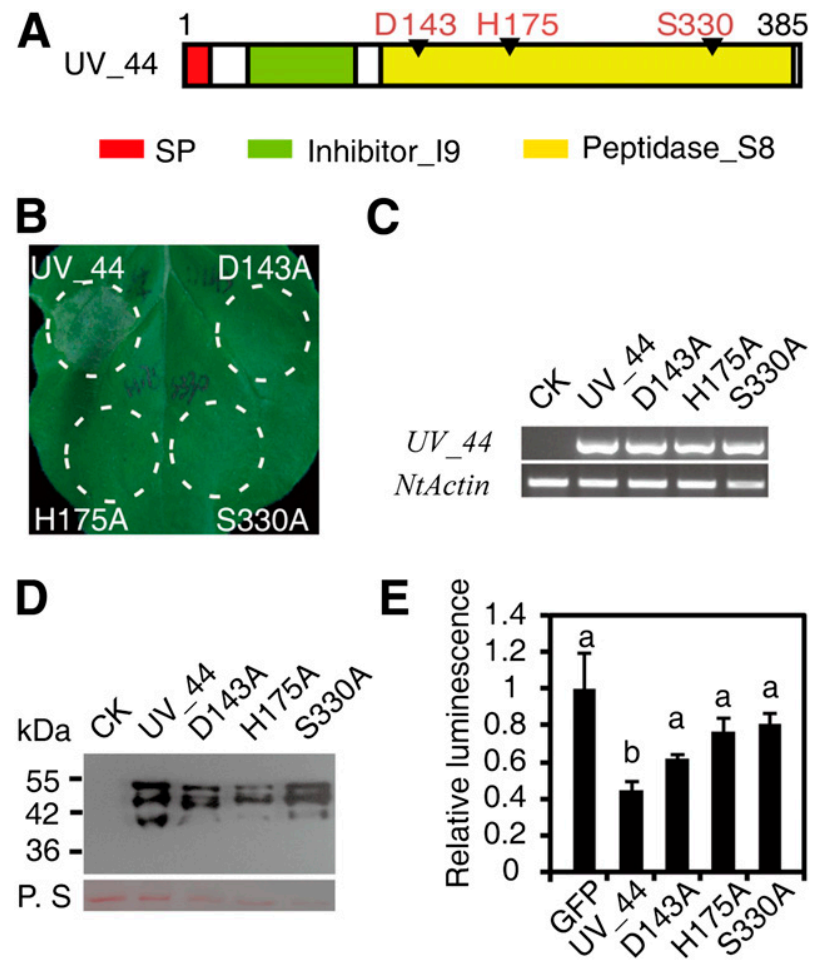

Fig. 6. The predicted catalytic triad of serine protease in UV_44 is essential for its cell death-inducing ability. A, The predicted domain structure of UV_44, a putative serine protease. SP = signal peptide; Inhibitor_I9 is the N-terminal peptidase inhibitor I9 domain and Peptidase_S8, a conserved protease domain, in which the residues Asp143, His175, and Ser330 form the catalytic triad. B, The mutant proteins UV_44 ${ }^{\mathrm{D} 143 \mathrm{~A}}, \mathrm{UV} \_44^{\mathrm{H} 175 \mathrm{~A}}$, and UV_44 ${ }^{\mathrm{S} 330 \mathrm{~A}}$ with point mutations in the predicted catalytic triad significantly lost the ability to induce cell death in Nicotiana benthamiana. $\mathbf{C}$, The mRNA expression level of $U V \_44$ and its mutant variants in the infiltrated leaves detected by reverse transcription-polymerase chain reaction. NtActin was used as an internal reference gene. D, The protein level of the wild-type UV_44 and mutant proteins in the infiltrated leaves detected by Western blotting. Ponceau S staining (P. S) of same blot to detect total protein. CK = uninfiltrated leaves. E, The luciferase activity in rice protoplasts cotransfected with the luciferase and the green fluorescent protein gene $(G F P)$, $U V \_44$, or its mutant gene constructs. Data are means \pm standard error. Different letters (a or b) indicate significant difference in the luciferase activity $(P<0.05$, Duncan's multiple-range test). only $N$-glycosylation site in UV_1423. Collectively, the data indicate that UV_1423 and UV_6205 are both $N$-glycosylated in plant cells.

In order to determine whether $N$-glycosylation affects the ability of the putative effectors to trigger cell death, LUC activity was tested in rice protoplasts cotransfected with LUC and effector gene constructs. LUC activity in UV_1423 ${ }^{\mathrm{N} 49 \mathrm{G}}$ transfected protoplasts was significantly higher than that in UV_1423-transfected protoplasts, suggesting that the cell death-inducing ability of UV_1423 ${ }^{\mathrm{N} 49 \mathrm{G}}$ is reduced (Fig. 8C). Although luminescence intensity in the protoplasts transfected with UV_6205 and its mutants with single point mutations was similar, LUC activity in UV_6205 ${ }^{\mathrm{N} 39 \mathrm{G} / \mathrm{N} 53 \mathrm{G}}$-transfected protoplasts was significantly lower, indicating that its ability to induce cell death is enhanced (Fig. 8C). Therefore, these results indicate that $\mathrm{N}$-glycosylation at least partly affects the function of putative effector proteins in $U$. virens.

\section{DISCUSSION}

The effector proteins secreted by filamentous fungal pathogens play essential roles in the host-pathogen interactions (Giraldo and Valent 2013; Stergiopoulos and de Wit 2009). The U. virens
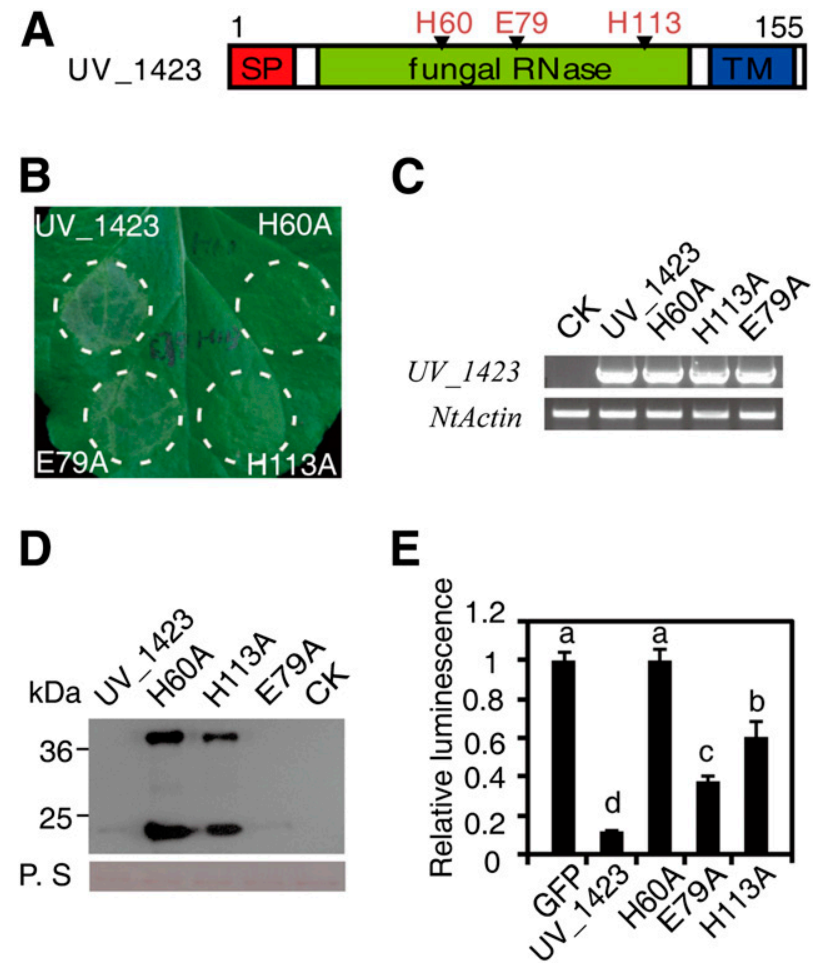

Fig. 7. The predicted RNase active site of UV_1423 is required for its cell death-triggering ability. A, The predicted domain structure of UV_1423, a putative fungus-specific RNase. $\mathrm{SP}=$ signal peptide; fungal $\mathrm{RNase}=\mathrm{a}$ conserved fungus-specific RNase domain including His60, Glu79, and His113, the predicted key residues necessary for the RNase activity; TM = transmembrane domain. B, The mutant proteins $\mathrm{UV}_{-} 1423^{\mathrm{H} 60 \mathrm{~A}}$ and UV_1423 ${ }^{\mathrm{H} 113 \mathrm{~A}}$ lost the ability to induce cell death, while UV_1423 ${ }^{\mathrm{E} 79 \mathrm{~A}}$ induced weak cell death in Nicotiana benthamiana leaves. C, The mRNA expression level of $U V_{-} 1423$ and its mutant variants in the infiltrated leaves detected by reverse transcription-polymerase chain reaction. NtActin was used as an internal control gene. D, The protein expression level of the wildtype UV_1423 and mutant proteins in the infiltrated leaves detected by Western blotting. Ponceau S staining (P. S) of the same blot to detect total protein. $\mathrm{CK}=$ uninfiltrated leaves. $\mathbf{E}$, The luciferase activity in rice protoplasts cotransfected with the luciferase and green fluorescent protein gene $(G F P), U V_{-} 1423$, or its mutant gene constructs. Data are means \pm standard error. Different letters (a through d) indicate significant difference in the luciferase activity $(P<0.05$, Duncan's multiple-range test). 
genome encodes more than 600 secreted proteins, many of which are considered as candidates of effector proteins (Zhang et al. 2014). Expression profiling analyses demonstrated that many putative effector genes in $U$. virens were transcriptionally induced during rice infection, indicating that they play important roles in the interaction of rice and $U$. virens (Zhang et al. 2014). In this study, our experimental data demonstrated that 11 putative effectors caused nonhost cell death in $N$. benthamiana and that eight of them induced cell death or defense responses in rice. The National Center for Biotechnology Information gene ID, locus tag, geninfo identifier, and protein ID of these cell death-inducing factors in $U$. virens are summarized in Supplementary Table S2.

Transient expression assay in $N$. benthamiana by agroinfiltration has been used for identifying the $M$. oryzae effectors that induce nonhost cell death (Chen et al. 2013). Through this assay, 13 of 119 putative effectors in $U$. virens were demonstrated to trigger different levels of cell death phenotypes in $N$. benthamiana. Further experimental data indicate that 11 predicted secreted proteins among them are most likely effectors. First, the predicted SPs of the 11 putative effectors were functional to guide the secretion of the truncated invertase and, therefore, the invertase-deficient yeast was able to grow on YPRAA medium in the yeast secretion assay (Fig. 2). Second, the 11 putative effectors were all differentially regulated during $U$. virens infection of rice panicles (Fig. 3), which is a feature common to characterized effector proteins in filamentous fungal pathogens (Chen et al. 2013). A highly efficient transient protoplast system has been successfully utilized to detect hypersensitive cell death during gene-for-gene interactions in the rice-M. oryzae pathosystem (Okuyama et al. 2011; Yoshida et al. 2009). Using this assay, eight of the 11 putative effectors were demonstrated to have the ability to induce cell death in host rice (Fig. 4). These cell death-inducing factors might be recognized by $R$ genes and, thus, trigger ETI. The hypothesis seems contradictory to the finding that most of these peptides induced cell death in the cultivar LYP9, which is highly susceptible to RFS (Han et al. 2015). Possibly, the ETI during infection is suppressed by other $U$. virens effectors, causing compatible interaction of rice and the pathogen. Our previous study identified multiple candidate effectors that can suppress HR triggered by Burkholderia glumae in $N$. benthamiana (Zhang et al. 2014). Similar observations have been reported in other adapted plant pathogens, such as $M$. oryzae and $P$. sojae (Chen et al. 2013; Wang et al. 2011). Alternatively, these proteins are recognized by the plant's MAMP recognition machinery and, thus, induce PTI. Recently, it has been demonstrated that the $P$. sojae effector XEG1, when transiently expressed, induces host and nonhost cell death and acts as a novel MAMP (Ma et al. 2015). Interestingly, our and other studies revealed that many putative filamentous pathogen effectors trigger cell death in nonhost $N$. benthamiana and in host plants as well, indicating that defense machinery in plants is highly conserved or that plants have convergently evolved to recognize the same defense elicitors.

The effector genes in filamentous plant pathogens are frequently located in regions that are either lineage-specific, genepoor, or both, that are enriched for retrotransponson and other repetitive sequence elements (Ma et al. 2010; Xue et al. 2012). These effectors, when being recognized, are subject to highspeed positive selection, allowing the pathogen to diversify its effector repertoire rapidly and to evade recognition by plant $R$ genes (Raffaele and Kamoun 2012; Zhang et al. 2014). As a consequence, fungal effectors generally share a relatively low amino acid sequence similarity among closely related fungal species (Zhang et al. 2014). Through Pfam and BLAST searches, no homolog or any identified functional motif or domain was identified for most of the 11 effectors except UV_44, UV_1423, and UV_5851. UV_5851 was predicted to have a novel MD-2-related lipid recognition (ML) domain implicated in lipid recognition. The ML domain-containing
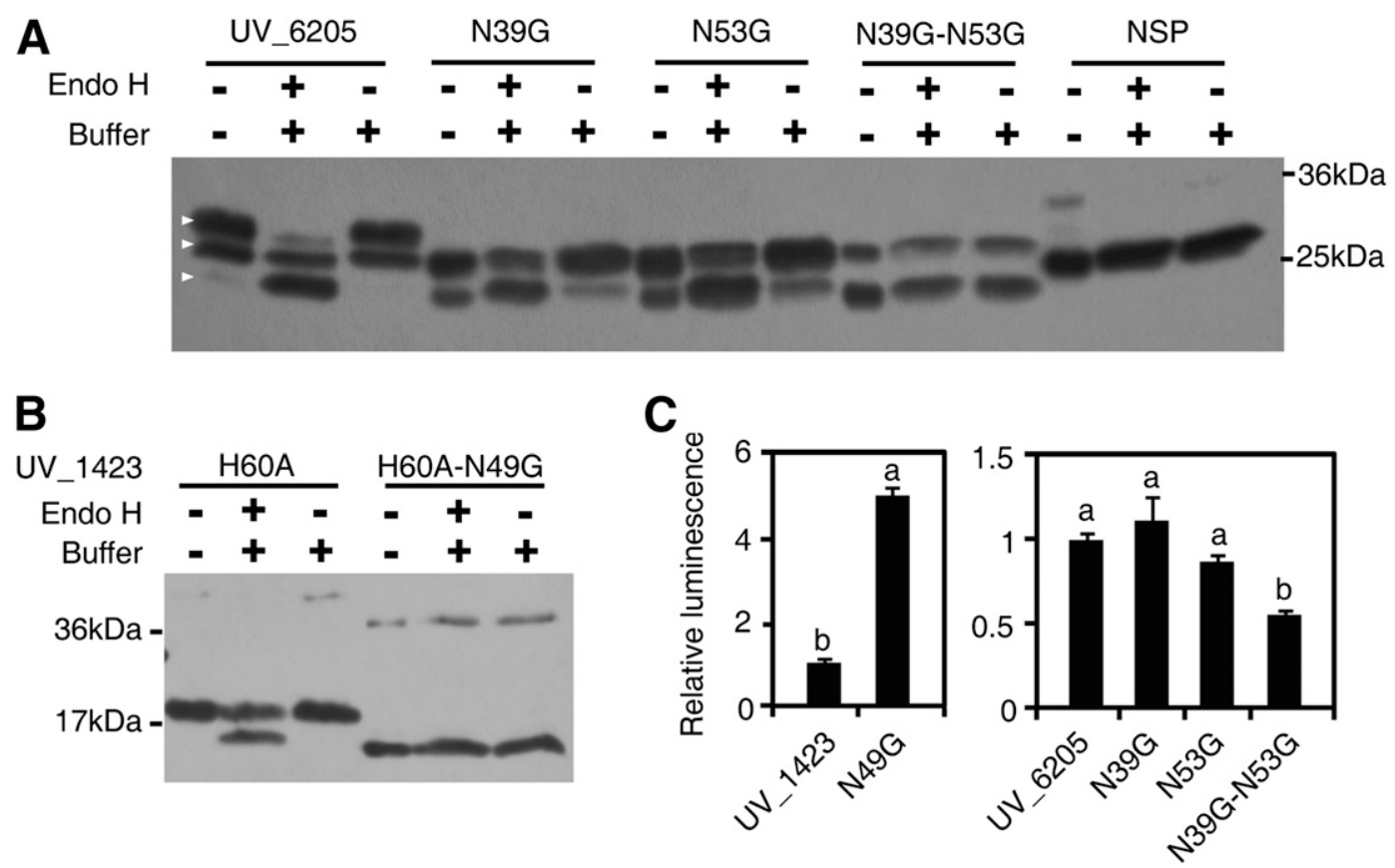

Fig. 8. The secreted proteins UV_6205 and UV_1423 are $N$-glycosylated proteins in plants. A, Deglycosylation analysis for the secreted protein UV_6205 and its mutant proteins with point mutations in putative $N$-glycosylaion sites Asn39 and Asn53 transiently expressed in rice protoplasts. B, Deglycosylation analysis for the mutant secreted proteins UV_1423 $3^{\mathrm{H} 60 \mathrm{~A}}$ and UV_1423 ${ }^{\mathrm{H} 60 \mathrm{~A} / \mathrm{N} 49 \mathrm{G}}$ with a point mutation at the putative glycosylation site Asn49 transiently expressed in rice protoplasts. Total protein extracts were treated with Endo $\mathrm{H}$ or buffer only before immunoblotting. Different bands indicated by white triangles are caused by posttranslational $N$-glycosylation. C, The luciferase activity in rice protoplasts cotransfected with the luciferase and $U V \_1423, U V \_6205$, or its mutant gene constructs. Data are means \pm standard error. Different letters (a or b) indicate significant difference in the luciferase activity $(P<0.05$, Duncan's multiple-range test). 
proteins have been reported to be related to innate immunity in mammals and in plants (Fridborg et al. 2013). However, no fungal effector with the ML domain has been reported so far and its functions in inducing cell death need to be further explored. UV_44 contains conserved peptidase inhibitor_I9 and peptidase_S8 domains. The UV_44 homolog in Rhizoctonia solani has been previously shown to induce HR in rice and maize (Zheng et al. 2013). We further revealed that the catalytic triad in the predicted peptidase_S8 domain was indispensable for its cell death-eliciting ability, indicating that the activity of serine peptidase is required for its function (Fig. 6). UV_1423 was predicted to be a fungus-specific RNase-like protein that triggered a rapid and severe cell death in $N$. benthamiana and in rice (Figs. 1 and 4). In contrast, BEC1011, a secreted RNaselike effector in Blumeria graminis f. sp. hordei, was shown to interfere with pathogen-induced host cell death specifically. Both BEC1011 and another RNase-like effector, BEC1054, contributed to B. graminis infection (Pliego et al. 2013). Different from the putative RNase active sites of BEC1011 and BEC1054, which are not conserved, key amino acid residues for RNase activity in UV_1423 were highly conserved. We showed that these conserved key residues were essential for its cell death-inducing activity, suggesting that UV_1423 is a functional RNase in plants (Fig. 7). By contrast, the contribution of BEC1011 and BEC1054 in B. graminis infection might not relate to RNase activity but, rather, host RNA binding or RNase scaffold (Pliego et al. 2013). These findings suggest that these similar effectors in different pathogenic fungi might function in the host-pathogen interaction with different mechanisms.

The SPs of the tested secreted proteins were all required for their ability to induce cell death in $N$. benthamiana and in rice protoplasts (Fig. 5). A similar phenomenon was observed for $M$. oryzae effector proteins. The full-length effectors MoCDIP1 to MoCDIP5 are able to trigger cell death in rice protoplasts, but the truncated versions of these proteins without SPs are not (Chen et al. 2013). The SP of XEG1, an apoplastic effector, is also required for its cell death-inducing ability (Ma et al. 2015). Interestingly, many oomycete RxLR effectors, such as AVR $3 \mathrm{a}^{\mathrm{KI}}$, ATR1 ${ }^{\mathrm{NdW} B}$, and ATR13, when directly expressed in planta, did not require a SP to trigger HR and are, therefore, recognized inside the plant cytoplasm (Morgan and Kamoun 2007). The requirement of SP for secreted proteins to induce cell death in plants indicates that these proteins might function in the extracellular space. These proteins without SPs cannot be secreted into the extracellular matrix, in which proteins are recognized by plasma membrane-bound pattern recognition receptors. Alternatively, these secreted proteins might be translocated into the cell after their secretion and trigger cell death after being recognized by cytoplasmic receptors. However, functionality and recognition of these secreted proteins in the cytosol may require proper processing, correct folding, and specific modifications, such as posttranslational glycosylation during their passage through the secretory pathway in the endoplasmic reticulum (ER) and the Golgi apparatus. Therefore, the exact localization of these proteins in plant cells needs to be further elucidated.

As a common posttranslational modification in eukaryotic cells, $N$-linked glycosylation of secreted proteins has been demonstrated to be directly associated with protein folding, stability, quality control, sorting, and secretion, and even sometimes to be recognized as a "tag" indirectly (Helenius and Aebi 2004). Most effector glycoproteins require their $N$-linked glycans for more efficient secretion in the ER and the Golgi complex (Helenius and Aebi 2004). However, biological significance of $N$-glycosylation of effector proteins in plantpathogenic fungi has not been accurately elucidated so far. Recently, $N$-glycosylation of effector proteins was shown to be important for $M$. oryzae to suppress host innate immunity
(Chen et al. 2014). In this study, six of 11 putative effector proteins were predicted by the NetNGlyc 1.0 Server to be $N$-glycosylated. Through de-glycosylation analyses and sitedirected mutagenesis of the predicted $\mathrm{N}$-glycosylation sites, UV_1423 and UV_6205 were proven to be $N$-glycosylated (Fig. 8). The data suggest that $N$-glycosylation is a common feature for fungal effectors, particularly for apoplastic effectors. Notably, the fully deglycosylated UV_6205 protein showed double bands in Western blots, suggesting that the protein might be subject to one or more other posttranslational modifications (Fig. 8). More interestingly, experimental data demonstrated that the mutations on the $N$-glycosylation sites of UV_1423 and UV_6205 affected the ability of inducing cell death (Fig. 8C). UV_1423 ${ }^{\mathrm{N} 49 \mathrm{G}}$ partially lost the cell death-inducing activity in rice protoplast, suggesting that $\mathrm{N}$-glycosylation has a positive effect on the ability of UV_1423 to induce cell death. However, UV_6205 ${ }^{\mathrm{N} 39 \mathrm{G} / \mathrm{N} 53 \mathrm{G}}$, with double point mutations, has a stronger effect on inhibition of LUC activity in rice protoplasts, indicating that $\mathrm{N}$-glycosylation possibly masks cell death-eliciting determinants of the protein. A similar observation has been reported for flagellin of the rice pathogen Acidovorax avenae. Acidovorax avenae $\mathrm{K} 1$ flagellin induced much stronger immune responses after deglycosylation (Hirai et al. 2011). Therefore, $N$-glycosylation influences biological functions of secreted proteins in the plantpathogen interaction through different mechanisms.

In the study, we identified and characterized several types of secreted proteins, probably effectors, in $U$. virens that induce plant cell death or defense machinery. However, precise molecular mechanisms describing how these secreted proteins are involved in the rice- $U$. virens interaction remain to be further elucidated.

\section{MATERIALS AND METHODS}

Bacterial strains, plant materials, and growth conditions.

The virulent $U$. virens isolates $\mathrm{UV}-8 \mathrm{~b}$ and $\mathrm{P} 1$ used in this study were cultured in PSA medium (boiled extracts of $200 \mathrm{~g}$ of fresh potato, $20 \mathrm{~g}$ of sucrose, and $14 \mathrm{~g}$ of agar per liter). $N$. benthamiana plants were grown in growth chambers under a $25^{\circ} \mathrm{C}, 14-\mathrm{h}$ day and $23^{\circ} \mathrm{C}, 10$-h night cycle. Agrobacterium tumefaciens EHA105 was cultured in Luria Bertani medium $(0.5 \%$ yeast extract, $1 \%$ tryptone, $1 \% \mathrm{NaCl})$ and was used for transient expression. The yeast strain YTK12 was cultured in YPDA medium (1\% yeast extract, $2 \%$ peptone, $2 \%$ glucose, $0.003 \%$ adenine hemisulfate, $2 \%$ agar). Antibiotics were used at the following concentrations $\left(\mu \mathrm{g} \mathrm{m}{ }^{-1}\right)$ : ampicillin, 100; kanamycin, 50; rifampin, 25. All experiments were repeated at least three times with similar results, unless noted.

\section{RNA isolation and plasmid construction of $U$. virens putative effector genes.}

Total RNA was extracted from $U$. virens, $U$. virens-inoculated rice panicles or agrobacterium-infiltrated $N$. benthamiana leaves, using an Ultrapure RNA isolation kit according to the manufacturer's instructions (CWBIO). The quantity and quality of isolated RNA were determined by NanoDrop 2000 (Thermo Scientific). Complementary DNA was synthesized using reverse transcriptase M-MLV (Invitrogen). Secreted proteins and putative effectors in $U$. virens were predicted in our previous study (Zhang et al. 2014). The full-length and truncated secreted protein-encoding genes were amplified with fast $P f u$ polymerase (TransGen), using cDNAs as template with the respective primer sets (Supplementary Tables S3 and S4). PCR products were digested with the corresponding restriction enzymes and were subcloned into pUC19-35S-FLAG-RBS (Li et al. 2005). All constructs were confirmed by sequencing. The inserted DNA sequence, together with the FLAG sequence in pUC19-35S-FLAG-RBS, was 
released by XhoI and SpeI and was religated into pTA7001 (Aoyama and Chua 1997).

\section{Site-directed mutagenesis.}

Site-directed mutagenesis was performed via circular PCR, using the pUC19-35S-FLAG-RBS gene constructs as templates. PCR was performed using $P f u$ Ultra DNA polymerase (Stratagene) for 18 thermal cycles $\left(30 \mathrm{~s}\right.$ at $95^{\circ} \mathrm{C}, 1 \mathrm{~min}$ at $55^{\circ} \mathrm{C}$, and $5 \mathrm{~min}$ at $68^{\circ} \mathrm{C}$ ). The resultant products were transformed into Escherichia coli DH5 $\alpha$ competent cells after DpnI digestion of the template plasmid DNA at $37^{\circ} \mathrm{C}$ for $1 \mathrm{~h}$. The constructed plasmids with point mutations were all confirmed by sequencing (Supplementary Table S5). The mutated genes with the FLAG-tag sequence were cleaved and religated into pTA7001 (Aoyama and Chua 1997).

\section{Agrobacterium tumefaciens-mediated transient gene expression.}

The pTA7001-based gene constructs were transformed into A. tumefaciens EHA105, using the freeze-thaw method (An et al. 1989). The overnight cultured A. tumefaciens strains with different gene constructs were harvested, were washed three times with sterile double-distilled $\mathrm{H}_{2} \mathrm{O}$, and were then resuspended in infiltration buffer (10 mM MES, pH 5.7, $10 \mathrm{mM}$ $\mathrm{MgCl}_{2}$, and $150 \mu \mathrm{M}$ acetosyringone) to cell density at an optical density at $600 \mathrm{~nm}$ of 0.5 . After standing at room temperature for $3 \mathrm{~h}$, A. tumefaciens cultures were pressure-infiltrated into the leaves of 4-week-old $N$. benthamiana plants using needleless syringes. A. tumefaciens strains carrying the pTA7001 empty vector or pTA7001-GFP were infiltrated as controls. The infiltrated leaves were sprayed with a $30-\mu \mathrm{M}$ DEX solution to induce gene expression at $16 \mathrm{~h}$ after infiltration. Cell-death symptoms were observed at 2 to 4 days after DEX spraying and were photographed at 5 days after infiltration.

\section{Rice protoplast transformation}

\section{and luminescence measurement.}

Rice protoplast isolation and transformation were performed as described previously (Chen et al. 2006; Zhang et al. 2011). The seedlings of rice cultivars Nipponbare and LYP9 were grown on $1 / 2 \times$ Murashige Skoog medium with $2 \%$ sucrose and $0.3 \%$ phytagel at $28^{\circ} \mathrm{C}$ in the dark for 10 to 12 days. The etiolated seedlings were cut into approximately $0.5-\mathrm{mm}$ strips, using a surgical blade. Sliced stripes were incubated in $20 \mathrm{ml}$ of enzyme solution (0.6 M mannitol, $1 \%$ cellulase RS, $0.5 \%$ macerozyme R10, $0.1 \%$ bovine serum albumin, $1 \mathrm{mM} \mathrm{CaCl}$, $5 \mathrm{mM} \beta$-mercaptoethanol, $10 \mathrm{mM}$ MES, $\mathrm{pH}$ 5.7) in a sterile Erlenmeyer flask at $28^{\circ} \mathrm{C}$ for $6 \mathrm{~h}$ in the dark with gentle shaking (approximately $70 \mathrm{rpm}$ ). The protoplasts were pelleted by centrifugation at 1,500 rpm (Centrifuge 5810R, Eppendorf) for 4 min after the enzyme solution was collected through filtration. The remaining debris was washed twice with W5 medium (154 mM NaCl, $125 \mathrm{mM} \mathrm{CaCl}_{2}, 5 \mathrm{mM} \mathrm{KCl}, 2 \mathrm{mM}$ MES, pH 5.7) to release more protoplasts. For transfection, the protoplasts were resuspended with an appropriate volume of MMG buffer (0.8 M mannitol, $1 \mathrm{mM} \mathrm{MgCl} 2,4 \mathrm{mM}$ MES, $\mathrm{pH}$ 5.7) to the density of $1.5 \times 10^{6}$ to $2.5 \times 10^{6}$ protoplasts per milliliter. Individual pUC19-35S-FLAG-RBS construct and pJD301-35SLUC plasmid DNA (10 $\mu \mathrm{g}$ each) were mixed with $200 \mu \mathrm{l}$ of suspended protoplasts and $220 \mu \mathrm{l}$ of PEG solution (40\% PEG $4000,1 \mathrm{mM} \mathrm{CaCl}, 0.6 \mathrm{M}$ mannitol) by gently shaking and were incubated at $28^{\circ} \mathrm{C}$ for $10 \mathrm{~min}$. W5 medium $(1.0 \mathrm{ml})$ was then added into the protoplasts to dilute PEG. The protoplasts were pelleted, washed, and resuspended with W5 medium, and were then kept at $28^{\circ} \mathrm{C}$ in the dark. After 16 to $36 \mathrm{~h}$ of incubation, the protoplasts were collected and were incubated with $100 \mu \mathrm{l}$ of extraction buffer ( $50 \mathrm{mM}$ Tris-Cl, $25 \mathrm{mM}$ EDTA,
$250 \mathrm{mM} \mathrm{NaCl}, 10 \%$ glycerol, $0.1 \%$ Triton X-100, $20 \mathrm{mM}$ dithiothreitol [DTT]) for protein extraction. The LUC activity was measured using a microplate reader after the mixture of extracted proteins $(20 \mu \mathrm{l})$ with the substrate luciferin $(1 \mathrm{mM}$, $20 \mu \mathrm{l})$ and $100 \mu \mathrm{l}$ of Tricine buffer $(20 \mathrm{mM}$ Tricine, $27 \mathrm{mM}$ $\mathrm{MgSO}_{4}+\cdot 7 \mathrm{H}_{2} \mathrm{O}, 0.1 \mathrm{mM}$ EDTA, 2 mM DTT, $5 \mu \mathrm{M}$ ATP, pH 7.8). Viability of transfected protoplasts was determined by staining with $50 \mu \mathrm{g}$ of fluorescein diacetate (FDA) per milliliter at $36 \mathrm{~h}$ after transfection. The FDA-stained vital cells were counted by thrombocytometer.

\section{Measurement of ion leakage from leaf discs of Nicotiana benthamiana.}

Ion leakage was measured to evaluate cell death in the inoculated leaves as described previously (Mittler et al. 1999; Yu et al. 2012). Briefly, five leaf discs (9 $\mathrm{mm}$ diameter) were collected and incubated on distilled water $(5 \mathrm{ml})$ for $3 \mathrm{~h}$ at room temperature. The conductivity of the bathing solution was measured with a conductivity meter (FE30; Mettler Toledo). After leaf discs were returned to the bathing solution and boiled in sealed tubes, the conductivity of the solution was measured again. The conductivity ratio was calculated as ion leakage.

\section{Validation of predicted SPs.}

Functional validation of the predicted SP of putative effectors in $U$. virens was conducted using a yeast secretion assay (Jacobs et al. 1997). The yeast signal sequence trap vector pSUC2T7M13ORI (pSUC2), which carries a truncated invertase gene lacking the start codon and SP coding sequence, was used in this assay. The predicted SP coding sequences of $U$. virens candidate effector genes were amplified and cloned as EcoRIXhoI fragments into pSUC2 (Oh et al. 2009; Tian et al. 2011) (Supplementary Table S6). The pSUC2-derived plasmid $(0.5 \mu \mathrm{g})$ was transformed into the invertase-deficient yeast strain YTK12 (SUC2-) using the Frozen-EZ yeast transformation II kit (Zymo Research). Transformants were selected on yeast minimal tryptophan dropout medium (CMD-W medium, $0.67 \%$ yeast $\mathrm{N}$ base without amino acids, $0.075 \%$ tryptophan dropout supplement, $2 \%$ sucrose, $0.1 \%$ glucose, and $2 \%$ agar). Yeast colonies were replica-plated onto YPRAA plates (1\% yeast extract, $2 \%$ peptone, $2 \%$ raffinose, and antimycin $\mathrm{A}$ at $2 \mu \mathrm{g} \mathrm{l^{-1 }}$ ) for invertase secretion assays.

\section{$U$. virens inoculation and quantitative real time RT-PCR.}

Injection inoculation of the $U$. virens isolate $\mathrm{P} 1$ into rice panicles of the RFS resistant Oryza sativa L. subsp. indica cultivar IR28 and highly susceptible LYP9 was performed as described previously (Han et al. 2015). The inoculated panicles were harvested at $0,24,48$, and $96 \mathrm{hpi}$, were immediately frozen in liquid nitrogen, and were then kept at $-70^{\circ} \mathrm{C}$ for RNA isolation.

Quantitative real time (q)RT-PCR was performed with SYBR premix ex Taq (TaKaRa), using the ABI PRISM 7000 sequence detection system (Applied Biosystems) according to the manufacturer's instructions. The expression level of candidate effector genes was calculated relative to $\alpha$-tubulin of $U$. virens, which was used as internal reference. The primer sets used for qRT-PCR and RT-PCR are listed in Supplementary Table S7.

\section{Protein extraction and immunoblotting.}

$N$. benthamiana leaves infiltrated with A. tumefaciens were harvested at $24 \mathrm{~h}$ after DEX spraying and were ground in liquid nitrogen. The powder was incubated with $1 \times$ sodium dodecyl sulfate (SDS)-polyacrylamide gel electrophoresis sample buffer and were then boiled for $10 \mathrm{~min}$. Protein extracts from $N$. benthamiana leaves or transfected protoplasts were separated on a $12 \%$ SDSpolyacrylamide gel by electrophoresis. Separated proteins were 
electrophoretically blotted onto nitrocellulose membranes (Millipore) and were stained with $0.1 \%$ Ponceau $\mathrm{S}$ to visualize sample loading. The membranes were blocked with 5\% skimmed milk in TBS-T buffer (50 mM Tris-HCl, pH 7.5, $150 \mathrm{mM} \mathrm{NaCl}, 0.05 \%$ Tween 20) for $1 \mathrm{~h}$ at room temperature, were incubated in an anti-FLAG antibody solution (1:5,000 dilution) for $1 \mathrm{~h}$ at room temperature, and were washed thoroughly with TBS-T buffer. The blots were then incubated in horseradish peroxidaseconjugated antimouse secondary antibody (1:5,000 dilution in TBS-T) for $1 \mathrm{~h}$ at room temperature. After rinsing thoroughly, the immunoblots were incubated with the eECL Western substrate (CWBIO) and were then exposed with X-films.

\section{$N$-glycosylation analysis.}

Endo H (New England Biolabs) was used for the deglycosylation analysis of UV_1423 and UV_6205, according to the manufacturer's instructions. UV_1423 and UV_6205 with point mutations in the predicted $\mathrm{N}$-glycosylation sites were transiently expressed in $N$. benthamiana and in rice protoplasts via the pTA7001 and pUC19-35S-FLAG-RBS constructs, respectively. Total proteins extracted from $N$. benthamiana leaves and rice protoplasts were treated with Endo $\mathrm{H}$ at $37^{\circ} \mathrm{C}$ for $1 \mathrm{~h}$ before immunoblotting.

\section{ACKNOWLEDGMENTS}

We thank J. Zhou at the Institute of Genetics and Developmental Biology, Chinese Academy of Sciences for the pUC19-35S-FLAG-RBS plasmid. The work is supported by the National Natural Science Foundation of China grant 31471728, the National High Technology Research and Development program of China 2012AA100703, Key Projects in the National Science \& Technology Pillar Program 2012BAD19B03, and the 111 project B13006 to W. Sun.

\section{LITERATURE CITED}

Ahmed, A. A., Pedersen, C., Schultz-Larsen, T., Kwaaitaal, M., Jørgensen, H. J. L., and Thordal-Christensen, H. 2015. The barley powdery mildew candidate secreted effector protein CSEP0105 inhibits the chaperone activity of a small heat shock protein. Plant Physiol. 168: 321-333.

An, G., Ebert, P. R., Mitra, A., and Ha, S. B. 1989. Binary vectors. Pages 1-19 in: Plant Molecular Biology Manual. S. B. Gelvin and R. A. Schilperoort, eds., Kluwer Academic Publishers, Dordrecht, Netherlands.

Aoyama, T., and Chua, N. H. 1997. A glucocorticoid-mediated transcriptional induction system in transgenic plants. Plant J. 11:605-612.

Blümke, A., Falter, C., Herrfurth, C., Sode, B., Bode, R., Schäfer, W., Feussner, I., and Voigt, C. A. 2014. Secreted fungal effector lipase releases free fatty acids to inhibit innate immunity-related callose formation during wheat head infection. Plant Physiol. 165:346-358.

Boller, T., and He, S. Y. 2009. Innate immunity in plants: An arms race between pattern recognition receptors in plants and effectors in microbial pathogens. Science 324:742-744.

Chauhan, R. S., Farman, M. L., Zhang, H. B., and Leong, S. A. 2002. Genetic and physical mapping of a rice blast resistance locus, $\mathrm{Pi}-\mathrm{CO} 39(\mathrm{t})$, that corresponds to the avirulence gene AVR1-CO39 of Magnaporthe grisea. Mol. Genet. Genomics 267:603-612.

Chen, S., Songkumarn, P., Venu, R. C., Gowda, M., Bellizzi, M., Hu, J., Liu, W., Ebbole, D., Meyers, B., Mitchell, T., and Wang, G. L. 2013. Identification and characterization of in planta-expressed secreted effector proteins from Magnaporthe oryzae that induce cell death in rice. Mol. Plant-Microbe Interact 26:191-202.

Chen, S., Tao, L., Zeng, L., Vega-Sanchez, M. E., Umemura, K., and Wang, G. L. 2006. A highly efficient transient protoplast system for analyzing defence gene expression and protein-protein interactions in rice. Mol. Plant Pathol. 7:417-427.

Chen, X. L., Shi, T., Yang, J., Shi, W., Gao, X., Chen, D., Xu, X., Xu, J. R., Talbot, N. J., and Peng, Y. L. 2014. $N$-glycosylation of effector proteins by an $\alpha-1,3-$ mannosyltransferase is required for the rice blast fungus to evade host innate immunity. Plant Cell 26:1360-1376.

Chisholm, S. T., Coaker, G., Day, B., and Staskawicz, B. J. 2006. Hostmicrobe interactions: Shaping the evolution of the plant immune response. Cell 124:803-814. de Jonge, R., van Esse, H. P., Kombrink, A., Shinya, T., Desaki, Y., Bours, R., van der Krol, S., Shibuya, N., Joosten, M. H., and Thomma, B. P. 2010. Conserved fungal LysM effector Ecp6 prevents chitin-triggered immunity in plants. Science 329:953-955.

Djamei, A., Schipper, K., Rabe, F., Ghosh, A., Vincon, V., Kahnt, J., Osorio, S., Tohge, T., Fernie, A. R., Feussner, I., Feussner, K., Meinicke, P., Stierhof, Y. D., Schwarz, H., Macek, B., Mann, M., and Kahmann, R. 2011. Metabolic priming by a secreted fungal effector. Nature 478: 395-398.

Dou, D., and Zhou, J. M. 2012. Phytopathogen effectors subverting host immunity: Different foes, similar battleground. Cell Host Microbe 12: 484-495.

Ekici, Ö. D., Paetzel, M., and Dalbey, R. E. 2008. Unconventional serine proteases: Variations on the catalytic Ser/His/Asp triad configuration. Protein Sci. 17:2023-2037.

Fridborg, I., Johansson, A., Lagensjö, J., Leelarasamee, N., Floková, K., Tarkowská, D., Meijer, J., and Bejai, S. 2013. ML3: A novel regulator of herbivory-induced responses in Arabidopsis thaliana. J. Exp. Bot. 64: 935-948.

Giraldo, M. C., and Valent, B. 2013. Filamentous plant pathogen effectors in action. Nat. Rev. Microbiol. 11:800-814.

Gu, B., Kale, S. D., Wang, Q., Wang, D., Pan, Q., Cao, H., Meng, Y., Kang, Z., Tyler, B. M., and Shan, W. 2011. Rust secreted protein Ps87 is conserved in diverse fungal pathogens and contains a RXLR-like motif sufficient for translocation into plant cells. PLoS One 6:e27217.

Han, Y., Zhang, K., Yang, J., Zhang, N., Fang, A., Zhang, Y., Liu, Y., Chen, Z., Hsiang, T., and Sun, W. 2015. Differential expression profiling of the early response to Ustilaginoidea virens between false smut resistant and susceptible rice varieties. BMC Genomics 16:955.

Helenius, A., and Aebi, M. 2004. Roles of N-linked glycans in the endoplasmic reticulum. Annu. Rev. Biochem. 73:1019-1049.

Hemetsberger, C., Herrberger, C., Zechmann, B., Hillmer, M., and Doehlemann, G. 2012. The Ustilago maydis effector Pep1 suppresses plant immunity by inhibition of host peroxidase activity. PLoS Pathog. 8:e1002684.

Hemetsberger, C., Mueller, A. N., Matei, A., Herrberger, C., Hensel, G., Kumlehn, J., Mishra, B., Sharma, R., Thines, M., Hückelhoven, R., and Doehlemann, G. 2015. The fungal core effector Pep1 is conserved across smuts of dicots and monocots. New Phytol. 206:1116-1126.

Hirai, H., Takai, R., Iwano, M., Nakai, M., Kondo, M., Takayama, S., Isogai, A., and Che, F. S. 2011. Glycosylation regulates specific induction of rice immune responses by Acidovorax avenae flagellin. J. Biol. Chem. 286:25519-25530.

Howden, A. J., and Huitema, E. 2012. Effector-triggered post-translational modifications and their role in suppression of plant immunity. Front. Plant Sci. 3:160.

Hu, M., Luo, L., Wang, S., Liu, Y., and Li, J. 2014. Infection processes of Ustilaginoidea virens during artificial inoculation of rice panicles. Eur. J. Plant Pathol. 139:67-77.

Jacobs, K. A., Collins-Racie, L. A., Colbert, M., Duckett, M., Golden-Fleet, M., Kelleher, K., Kriz, R., LaVallie, E. R., Merberg, D., Spaulding, V., Stover, J., Williamson, M. J., and McCoy, J. M. 1997. A genetic selection for isolating cDNAs encoding secreted proteins. Gene 198:289-296.

Jones, J. D., and Dangl, J. L. 2006. The plant immune system. Nature 444: 323-329.

Kanzaki, H., Yoshida, K., Saitoh, H., Fujisaki, K., Hirabuchi, A., Alaux, L., Fournier, E., Tharreau, D., and Terauchi, R. 2012. Arms race coevolution of Magnaporthe oryzae AVR-Pik and rice Pik genes driven by their physical interactions. Plant J. 72:894-907.

Li, X., Lin, H., Zhang, W., Zou, Y., Zhang, J., Tang, X., and Zhou, J. M. 2005. Flagellin induces innate immunity in nonhost interactions that is suppressed by Pseudomonas syringae effectors. Proc. Natl. Acad. Sci. U.S.A. 102:12990-12995.

Luderer, R., Takken, F. L., de Wit, P. J., and Joosten, M. H. 2002. Cladosporium fulvum overcomes $C f$-2-mediated resistance by producing truncated AVR2 elicitor proteins. Mol. Microbiol. 45:875-884.

Luehrsen, K. R., de Wet, J. R., and Walbot, V. 1992. Transient expression analysis in plants using firefly luciferase reporter gene. Methods Enzymol. 216:397-414.

Ma, L. J., van der Does, H. C., Borkovich, K. A., Coleman, J. J., Daboussi, M. J., Di Pietro, A., Dufresne, M., Freitag, M., Grabherr, M., Henrissat, B., Houterman, P. M., Kang, S., Shim, W. B., Woloshuk, C., Xie, X., Xu, J. R., Antoniw, J., Baker, S. E., Bluhm, B. H., Breakspear, A., Brown, D. W., Butchko, R. A., Chapman, S., Coulson, R., Coutinho, P. M., Danchin, E. G., Diener, A., Gale, L. R., Gardiner, D. M., Goff, S., Hammond-Kosack, K. E., Hilburn, K., Hua-Van, A., Jonkers, W., Kazan, K., Kodira, C. D., Koehrsen, M., Kumar, L., Lee, Y. H., Li, L., Manners, J. M., Miranda-Saavedra, D., Mukherjee, M., Park, G., Park, J., Park, 
S. Y., Proctor, R. H., Regev, A., Ruiz-Roldan, M. C., Sain, D., Sakthikumar, S., Sykes, S., Schwartz, D. C., Turgeon, B. G., Wapinski, I., Yoder, O., Young, S., Zeng, Q., Zhou, S., Galagan, J., Cuomo, C. A., Kistler, H. C., and Rep, M. 2010. Comparative genomics reveals mobile pathogenicity chromosomes in Fusarium. Nature 464:367-373.

Ma, Z., Song, T., Zhu, L., Ye, W., Wang, Y., Shao, Y., Dong, S., Zhang, Z., Dou, D., Zheng, X., Tyler, B. M., and Wang, Y. 2015. A Phytophthora sojae glycoside hydrolase 12 protein is a major virulence factor during soybean infection and is recognized as a PAMP. Plant Cell 27: 2057-2072.

Macho, A. P., and Zipfel, C. 2014. Plant PRRs and the activation of innate immune signaling. Mol. Cell 54:263-272.

Mentlak, T. A., Kombrink, A., Shinya, T., Ryder, L. S., Otomo, I., Saitoh, H., Terauchi, R., Nishizawa, Y., Shibuya, N., Thomma, B. P., and Talbot, N. J. 2012. Effector-mediated suppression of chitin-triggered immunity by Magnaporthe oryzae is necessary for rice blast disease. Plant Cell 24: 322-335.

Mittler, R., Herr, E. H., Orvar, B. L., van Camp, W., Willekens, H., Inzé, D., and Ellis, B. E. 1999. Transgenic tobacco plants with reduced capability to detoxify reactive oxygen intermediates are hyperresponsive to pathogen infection. Proc. Natl. Acad. Sci. U.S.A. 96:14165-14170.

Morgan, W., and Kamoun, S. 2007. RXLR effectors of plant pathogenic oomycetes. Curr. Opin. Microbiol. 10:332-338.

Mueller, A. N., Ziemann, S., Treitschke, S., Aßmann, D., and Doehlemann, G. 2013. Compatibility in the Ustilago maydis-maize interaction requires inhibition of host cysteine proteases by the fungal effector Pit2. PLoS Pathog. 9:e1003177.

Oh, S. K., Young, C., Lee, M., Oliva, R., Bozkurt, T. O., Cano, L. M., Win, J., Bos, J. I., Liu, H. Y., van Damme, M., Morgan, W., Choi, D., Van der Vossen, E. A., Vleeshouwers, V. G., and Kamoun, S. 2009. In planta expression screens of Phytophthora infestans RXLR effectors reveal diverse phenotypes, including activation of the Solanum bulbocastanum disease resistance protein Rpi-blb2. Plant Cell 21:2928-2947.

Okuyama, Y., Kanzaki, H., Abe, A., Yoshida, K., Tamiru, M., Saitoh, H., Fujibe, T., Matsumura, H., Shenton, M., Galam, D. C., Undan, J., Ito, A., Sone, T., and Terauchi, R. 2011. A multifaceted genomics approach allows the isolation of the rice Pia-blast resistance gene consisting of two adjacent NBS-LRR protein genes. Plant J. 66:467-479.

Park, C. H., Chen, S., Shirsekar, G., Zhou, B., Khang, C. H., Songkumarn, P., Afzal, A. J., Ning, Y., Wang, R., Bellizzi, M., Valent, B., and Wang, G. L. 2012. The Magnaporthe oryzae effector AvrPiz-t targets the RING E3 ubiquitin ligase APIP6 to suppress pathogen-associated molecular pattern-triggered immunity in rice. Plant Cell 24:4748-4762.

Pliego, C., Nowara, D., Bonciani, G., Gheorghe, D. M., Xu, R., Surana, P., Whigham, E., Nettleton, D., Bogdanove, A. J., Wise, R. P., Schweizer, P., Bindschedler, L. V., and Spanu, P. D. 2013. Host-induced gene silencing in barley powdery mildew reveals a class of ribonuclease-like effectors. Mol. Plant-Microbe Interact 26:633-642.

Raffaele, S., and Kamoun, S. 2012. Genome evolution in filamentous plant pathogens: Why bigger can be better. Nat. Rev. Microbiol. 10:417-430.

Rep, M., van der Does, H. C., Meijer, M., van Wijk, R., Houterman, P. M., Dekker, H. L., de Koster, C. G., and Cornelissen, B. J. 2004. A small, cysteine-rich protein secreted by Fusarium oxysporum during colonization of xylem vessels is required for $I-3$-mediated resistance in tomato. Mol. Microbiol. 53:1373-1383

Rush, M., Shahjahan, A., Jones, J., and Groth, D. 2000. Outbreak of false smut of rice in Louisiana. Plant Dis. 84:100.

Schulze-Lefert, P., and Panstruga, R. 2011. A molecular evolutionary concept connecting nonhost resistance, pathogen host range, and pathogen speciation. Trends Plant Sci. 16:117-125.

Shan, T., Sun, W., Liu, H., Gao, S., Lu, S., Wang, M., Sun, W., Chen, Z., Wang, S., and Zhou, L. 2012. Determination and analysis of ustiloxins A and B by LC-ESI-MS and HPLC in false smut balls of rice. Int. J. Mol. Sci. 13:11275-11287

Singh, A., and Pophaly, D. 2010. An unusual rice false smut epidemic reported in Raigarh District, Chhattisgarh, India. Int. Rice Res. Notes 35:1-3.
Stam, R., Mantelin, S., McLellan, H., and Thilliez, G. 2014. The role of effectors in nonhost resistance to filamentous plant pathogens. Front. Plant Sci. 5:582.

Stergiopoulos, I., and de Wit, P. J. 2009. Fungal effector proteins. Annu. Rev. Phytopathol. 47:233-263.

Takagi, H., Uemura, A., Yaegashi, H., Tamiru, M., Abe, A., Mitsuoka, C., Utsushi, H., Natsume, S., Kanzaki, H., Matsumura, H., Saitoh, H., Yoshida, K., Cano, L. M., Kamoun, S., and Terauchi, R. 2013. MutMapGap: Whole-genome resequencing of mutant F2 progeny bulk combined with de novo assembly of gap regions identifies the rice blast resistance gene Pii. New Phytol. 200:276-283.

Tanaka, E., Ashizawa, T., Sonoda, R., and Tanaka, C. 2008. Villosiclava virens gen. nov., comb. nov., teleomorph of Ustilaginoidea virens, the causal agent of rice false smut. [Erratum: 2009, vol. 107, page 540.] Mycotaxon 106:491-501.

Tang, Y. X., Jin, J., Hu, D. W., Yong, M. L., Xu, Y., and He, L. P. 2013. Elucidation of the infection process of Ustilaginoidea virens (teleomorph: Villosiclava virens) in rice spikelets. Plant Pathol. 62:1-8.

Tian, M., Win, J., Savory, E., Burkhardt, A., Held, M., Brandizzi, F., and Day, B. 2011. 454 Genome sequencing of Pseudoperonospora cubensis reveals effector proteins with a QXLR translocation motif. Mol. PlantMicrobe Interact 24:543-553.

Van der Hoorn, R. A., Laurent, F., Roth, R., and De Wit, P. J. 2000. Agroinfiltration is a versatile tool that facilitates comparative analyses of Avr $9 / C f$-9-induced and Avr4/Cf-4-induced necrosis. Mol. Plant-Microbe Interact 13:439-446.

van Esse, H. P., Bolton, M. D., Stergiopoulos, I., de Wit, P. J., and Thomma, B. P. 2007. The chitin-binding Cladosporium fulvum effector protein Avr4 is a virulence factor. Mol. Plant-Microbe Interact 20:1092-1101.

Voigt, C. A., Schäfer, W., and Salomon, S. 2005. A secreted lipase of Fusarium graminearum is a virulence factor required for infection of cereals. Plant J. 42:364-375.

Wang, Q., Han, C., Ferreira, A. O., Yu, X., Ye, W., Tripathy, S., Kale, S. D., Gu, B., Sheng, Y., Sui, Y., Wang, X., Zhang, Z., Cheng, B., Dong, S., Shan, W., Zheng, X., Dou, D., Tyler, B. M., and Wang, Y. 2011 Transcriptional programming and functional interactions within the Phytophthora sojae RXLR effector repertoire. Plant Cell 23:2064-2086.

Xue, M., Yang, J., Li, Z., Hu, S., Yao, N., Dean, R. A., Zhao, W., Shen, M., Zhang, H., Li, C., Liu, L., Cao, L., Xu, X., Xing, Y., Hsiang, T., Zhang, Z., Xu, J. R., and Peng, Y. L. 2012. Comparative analysis of the genomes of two field isolates of the rice blast fungus Magnaporthe oryzae. PLoS Genet. 8:e1002869.

Yoshida, K., Saitoh, H., Fujisawa, S., Kanzaki, H., Matsumura, H., Yoshida K., Tosa, Y., Chuma, I., Takano, Y., Win, J., Kamoun, S., and Terauchi, R. 2009. Association genetics reveals three novel avirulence genes from the rice blast fungal pathogen Magnaporthe oryzae. Plant Cell 21: 1573-1591.

Yu, X., Tang, J., Wang, Q., Ye, W., Tao, K., Duan, S., Lu, C., Yang, X., Dong, S., Zheng, X., and Wang, Y. 2012. The RxLR effector Avh241 from Phytophthora sojae requires plasma membrane localization to induce plant cell death. New Phytol. 196:247-260.

Zhang, Y., Su, J., Duan, S., Ao, Y., Dai, J., Liu, J., Wang, P., Li, Y., Liu, B., Feng, D., Wang, J., and Wang, H. 2011. A highly efficient rice green tissue protoplast system for transient gene expression and studying light/chloroplast-related processes. Plant Methods 7:30.

Zhang, Y., Zhang, K., Fang, A., Han, Y., Yang, J., Xue, M., Bao, J., Hu, D., Zhou, B., Sun, X., Li, S., Wen, M., Yao, N., Ma, L. J., Liu, Y., Zhang, M., Huang, F., Luo, C., Zhou, L., Li, J., Chen, Z., Miao, J., Wang, S., Lai, J., Xu, J. R., Hsiang, T., Peng, Y. L., and Sun, W. 2014. Specific adaptation of Ustilaginoidea virens in occupying host florets revealed by comparative and functional genomics. Nat. Commun. 5:3849.

Zheng, A., Lin, R., Zhang, D., Qin, P., Xu, L., Ai, P., Ding, L., Wang, Y., Chen, Y., Liu, Y., Sun, Z., Feng, H., Liang, X., Fu, R., Tang, C., Li, Q., Zhang, J., Xie, Z., Deng, Q., Li, S., Wang, S., Zhu, J., Wang, L., Liu, H., and $\mathrm{Li}, \mathrm{P}$. 2013. The evolution and pathogenic mechanisms of the rice sheath blight pathogen. Nat. Commun. 4:1424. 